\title{
Antibacterial Activity of Textiles for Wound Treatment
}

\author{
By Eva Pinho, Graça Soares, and Mariana Henriques, University of Minho; and Martin Grootveld, De Montfort University
}

\begin{abstract}
Major advances in the development and use of antimicrobial textiles to control bacterial proliferation on wound beds continue. However, wound dressings are, in general, not included in standardized regimens for measuring and monitoring their antimicrobial effectiveness. This work adapts these methods to assess the antibacterial activity of textiles designed for wound healing purposes. Environmental conditions representative of those present at the wound site (i.e., moisture levels, infection, and available nutrients) were evaluated. This work shows that moisture levels were the environmental factor that had the greatest influence on the antimicrobial agent activities tested. These results suggest that it is possible to use the more representative environmental conditions present on the wound bed for in vitro screening of textile antimicrobial activity.
\end{abstract}

Key Terms

Antibacterial, Antimicrobial, Healing, Infections, Medical Textiles, Moisture Levels, Sweat, Wound Dressing

\section{Introduction}

In recent years, an increasing number of chronic wounds associated with various pathologies, such as arterial insufficiencies, chronic venous conditions, diabetes mellitus, and dermatological or immunological diseases, have been observed. Consequently, a wide range of wound care products have been commercialized to improve the quality of patients' lives. ${ }^{1-4}$

Microorganism deposition on the wound site is one of the major problems encountered at the wound bed. Associated infections increase the production of wound exudate, leading to more frequent replacements of wound dressings, causing pain to patients and increasing the probability of removing newly-formed skin. ${ }^{5,6}$

Despite the existence of many kinds of wound dressings, textiles are still the most widely used in view of their low cost. ${ }^{7}$ Moreover, the number of antimicrobial textiles for woundhealing purposes increases each year. The need for in vitro antimicrobial activity test methods to assess wound dressing effectiveness is of the utmost importance. ${ }^{5,8}$

Several standard methods have recently been proposed for assessing the antimicrobial properties of textiles, including both qualitative (AATCC Test Method (TM) 147:2011, ISO 20645:2004, and JIS L 1902:2008-Halo Method) and quantitative (AATCC TM 100:2004, ISO 20742:2013, and JIS L 10902:2008) methods. However, there is no consensus regarding the most appropriate method to use, and consequently, numerous published works offer adaptations to the standard methods or newly-developed approaches. Furthermore, as demonstrated in previous investigations, ${ }^{9,10}$ these methods have drawbacks related to the "real" or "optimized" conditions of use, and also consume time and materials.
The environmental conditions used are especially important in assessing antimicrobial textiles for wound treatment. Therefore, many published methods do not represent wound site conditions in vivo, such as infection or a high level of moisture arising from sweat or wound exudate.

Therefore, the aim of this work was to propose a modified method allowing a more realistic assessment of wounddressing textile antimicrobial activity based on the JIS L 1902: Adsorption Method.

\section{Experimental}

\section{Materials}

The microorganisms used in this study were the Grampositive bacterium Staphylococcus aureus (ATCC 6538) and Gram-negative bacterium Klebsiella pneumoniae (ATCC 11296), selected according to the standard JIS L 1902. ATCC is the American Type Culture Collection.

Cotton fabric ( $100 \%$ cotton, $\left.112.6 \mathrm{~g} / \mathrm{m}^{2}\right)$ was obtained from Lameirinho SA and used as a standard textile substrate. The diffusible agent (Ruco-bac AGP) was supplied by Rudolf Produtos Químicos SA, and the non-diffusible agent (Sanitized T99) was obtained from Clariant Químicos Lda.

The synthetic sweat solution used was based on the "acid sweat solution" described in the standard ISO 105-E04: 2008 $(0.5 \mathrm{~g} / \mathrm{L}$ of L-histidine monohydrochloride monohydrate, 5 $\mathrm{g} / \mathrm{L}$ of sodium chloride, and $2.2 \mathrm{~g} / \mathrm{L}$ of sodium dihydrogen orthophosphate dehydrate, $\mathrm{pH}$ 5.5).

\section{Procedures}

Antimicrobial Agent Fabric Treatment

Solutions of the diffusible agent were prepared with tap water to mimic textile industrial wet process conditions for 
each desired concentration $(0,0.5,1.25,2.5,3.75$, and $5 \mathrm{~g} /$ $\mathrm{mL})$. Cotton samples $(25 \times 60 \mathrm{~cm})$ were used. The samples were immersed in the diffusible agent solution at the desired concentration for $5.0 \mathrm{~min}$. Subsequently, the samples were padded with a wet pickup of $90 \%$ (as recommended by the supplier), and then dried at ambient temperature.

The non-diffusible agent samples were prepared using the procedure described above, with the exception of a wet pickup value of $80 \%$ (as suggested by the supplier). The concentrations of the solutions used were $0,0.082,0.205,0.41$, and $0.82 \mathrm{~g} / \mathrm{mL}$.

\section{Antimicrobial Assessment}

The absorption method described in JIS L 1902:2008 ${ }^{11}$ was used as a baseline for the proposed method. The JIS L 1902 absorption method was modified as follows. An inoculum was prepared in $20.0 \pm 0.1 \mathrm{~mL}$ of TSB (Tryptic Soy Broth, Merck) and incubated for a period of 18 to $24 \mathrm{~h}$ at $37 \pm 1{ }^{\circ} \mathrm{C}$ under agitation (120 rpm). Subsequently, the bacterial concentration was adjusted to $3 \times 10^{8}$ cells $/ \mathrm{mL}$ via absorbance readings, and based on a corresponding calibration curve. An aliquot of the above suspension $(400 \mu \mathrm{L})$ was added to 20 $\mathrm{mL}$ of TSB and incubated for $3.0 \mathrm{~h}$ at $37 \pm 1^{\circ} \mathrm{C}$. The bacterial concentration was again measured and $3 \times 10^{5}$ cells $/ \mathrm{mL}$ were obtained using a 20 -fold dilution of TSB (in distilled water). The specified volume of this inoculum was then added to each sample. Samples were incubated for 18 to $24 \mathrm{~h}$ at $37 \pm$ $1{ }^{\circ} \mathrm{C}$. Subsequently, $20 \mathrm{~mL}$ of physiological saline solution ( $8.5 \mathrm{~g}$ of $\mathrm{NaCl}$ and $2.0 \mathrm{~g}$ of nonionic surfactant Tween 20 (Sigma Chemical Co.) per liter) were added to the samples, which were then vortexed. The number of living bacteria was assessed by the serial dilution plate count method. ${ }^{11}$ All assays were performed in triplicate and repeated three times.

\section{Statistical Analysis}

An analysis of variance (ANOVA) was carried out to determine any significant differences between the standard conditions and the new adaptations. The data were processed with the Graphpad Prism program for Windows, version 6.

\section{Results and Discussion}

The development and availability of antimicrobial-treated textiles for wound-healing proposes have increased substantially in recent years. Adaptations of available antimicrobial test methods for testing these products are also in progress.

Several published works have used methodologies adapted from the standard, ${ }^{12-16}$ or, alternatively, have described newlydeveloped ones. ${ }^{17-20}$ However, this fails to guarantee the standardization of results, and the correct assessment of differences or similarities, among various research investigations.

The most common drawbacks found regarding adaptation to or creation of new methods include: 1) the application of qualitative methods (without complementary analysis) as quantitative methods, ${ }^{9} 2$ ) the reduced contact time of the textile material with bacteria, ${ }^{15,17,21,22} 3$ ) the reduced bacterial concentrations involved, ${ }^{13,17,23}$ and 4 ) the nature and relevance of the culture medium used. ${ }^{14,16,17,24,25}$

A previous study conducted by this group has shown that quantitative methods are more accurate and reliable than qualitative ones. It has also been reported that the JIS L:1902 - absorption method is the most sensitive method available to date. ${ }^{9}$ Therefore, this method was chosen as the baseline method against which adjustments for antibacterial activity assessment of textiles designed and developed for effective wound treatments were compared. The goal of this paper was to analyze the effect of technical and environmental variations on the test method. The method was then modified for a more realistic assessment of treated textile bactericidal activities optimized for wound healing, and not the activity of the antibacterial agents per se.

\section{Technical Adaptations}

Technical test method adaptation was assessed to reduce the economic burden associated with the disposable material used. Instead of the $50-\mathrm{mL}$ conical tubes utilized in the JIS L 1902 method, we used six-well plates as an incubation container device (for this adaptation, a control sample, cotton without any added antimicrobial agent, was used). The number of bacteria was assessed immediately after the sample was inoculated $(0.0 \mathrm{~h})$, and also after a $24 \mathrm{~h}$ incubation period. Using the conical tubes as an incubation device, the number of cells recovered after $24 \mathrm{~h}\left(2.51 \times 10^{9}\right.$ cells $\left./ \mathrm{mL}\right)$ was much greater than that present after the baseline $(0.0$ h) sample incubation period $\left(2.5 \times 10^{5}\right.$ cells $\left./ \mathrm{mL}\right)$. However, when the six-well plates were used, no bacteria were recovered from the sample subsequent to this incubation period, although immediately after inoculation, $2.5 \times 10^{5}$ cells $/ \mathrm{mL}$ were recovered from the textile on the six-well plate. The results obtained strongly suggested that the incubation device should permit a vortexing stage since, without this step, the microorganisms remain attached to the textile material, which renders growth assessments difficult, if not impossible.

For the remaining alterations, two antimicrobial agents already available on the market were used. The diffusible agent used, based on silver activity, exerts broad-spectrum and powerful antimicrobial actions with diffusible activity (i.e., the silver can migrate as $\operatorname{Ag}(\mathrm{I})$ ions from the textile material to the skin). Indeed, this antimicrobial activity is ascribable to this ion's ability to complex with and denature a range of extracellular proteins, and also to bind to critical biomolecules such as DNA and RNA, and, in this manner, disrupt their functions. ${ }^{26}$ The other agent used exerts a non-diffusible activity, and is based on a silicon-functional tetra-alkylammonium compound. In this case, quaternary ammonium functional 
groups are covalently linked to the textiles, which enhances their durability and resistance to repeated washing episodes to which the antimicrobial finishing agent is exposed. However, the antimicrobial agent cannot migrate from the textile to the surrounding environment.

Samples with increasing concentrations of both antimicrobial agents were prepared, and the influence of the sample's weight $(0.1 \mathrm{~g}$ or $0.4 \mathrm{~g})$ on its activity was assessed. Based on Fig. 1A, it was observed that the weight of fabric did not interfere with the sample's ability to kill bacteria, and that $1.25 \mathrm{~g} / \mathrm{mL}$ of diffusible agent was enough to destroy both bacteria. A similar behavior was detected for the non-diffusible agent (Fig. 1B), although a smaller concentration $(0.41$ $\mathrm{g} / \mathrm{mL}$ ) was needed to destroy all bacteria. Therefore, reductions in the sample size would have an economic benefit in view of the lower amounts of textiles and reagent volumes required for the assessment of their antibacterial activity, and hence the overall cost of the procedure will be reduced.

\section{Environmental Adaptations}

As noted above, the published or documented standards available are not applicable to wound dressings, and consequently the concentrations of microorganism and the volume of inoculum involved do not reflect the conditions found in healthy skin. Therefore, to predict the behavior of antimicrobial wound dressings during their contact period with the wound, such assessments should be conducted with environmental conditions as close as possible to those found at the wound site in vivo.

In the present work, we tested the efficiencies of textiles antibacterial activities when exposed to environmental conditions similar to the ones found on a wound site, such as 1) higher volumes of inoculum ( 100 and $200 \mu \mathrm{L}$ ) to mimic the high levels of moisture present in a wound, 2) different

(A)

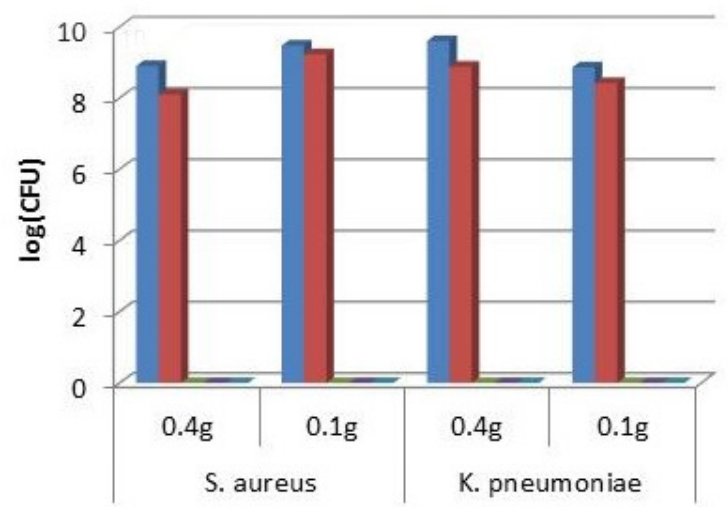

inoculum concentrations $\left(3 \times 10^{5}, 3 \times 10^{6}\right.$, and $3 \times 10^{7}$ cells/ $\mathrm{mL}$ ) were used since healthy skin has $10^{5}$ bacteria $/ \mathrm{cm}^{2}$ (at higher values than this the skin is considered to be infected), ${ }^{27}$ and 3) a synthetic sweat solution was used to provide similar nutrients to those available on the skin.

For efficient adaptation to environmental conditions, 0.10 g samples containing appropriate concentrations of each antimicrobial agent (i.e., those that allow the growth of both classes of bacteria (using $0.5 \mathrm{~g} / \mathrm{mL}$ and $0.205 \mathrm{~g} / \mathrm{mL}$ of the diffusible and non-diffusible agents, respectively) were used, since higher concentrations of both agents destroyed all of the bacteria under all conditions tested, and therefore the effects of these alterations were not discernable.

Both antibacterial agents were capable of killing Gram-positive and Gram-negative bacteria regardless of the inoculum concentration (Fig. 2). The diffusible agent was able to destroy $80 \%$ of S. aureus and $90 \%$ of K. pneunomiae. The death rate was lower for the non-diffusible agent, although $60 \%$ and $70 \%$ of the Gram-positive and Gram-negative bacteria were destroyed, respectively.

The inoculum volume had no effect on the antibacterial activity of the diffusible agent against S. aureus (Fig. 3A), since the percentage of killed cells were similar for all the volumes tested (between $84 \%$ and $87 \%$ ). For K. pneumoniae, the activity of this agent was reduced with increased inoculum volumes ( $86 \%, 32 \%$, and $22 \%$ of cell death, respectively). This loss of activity was also detected for the non-diffusible agent against $K$. pneumoniae, although less than that observed with the diffusible agent, as expected. Increases in inoculum volume caused a greater than $10 \%$ reduction in the bactericidal capacity of the non-diffusible agent. For S. aureus also, there was a diminished antibacterial activity of the non-diffusible agent when higher volumes were used

(B)

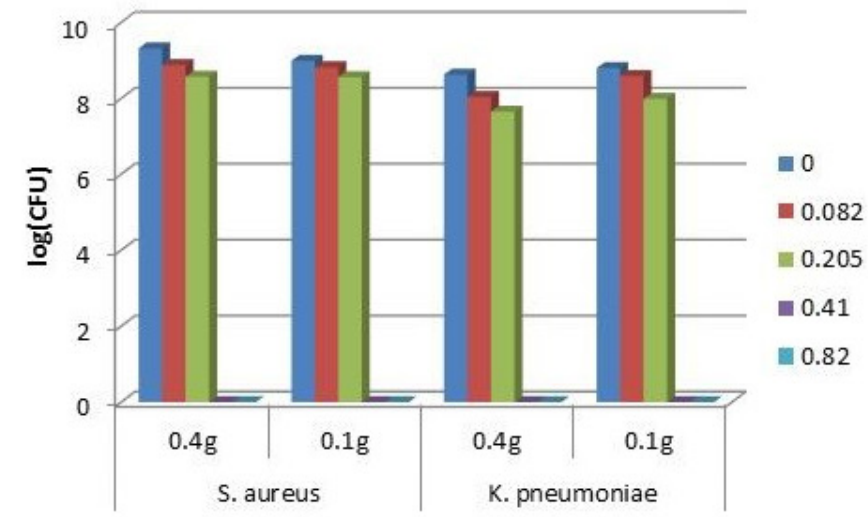

Fig. 1. Effect of the sample weight (g) on textile antibacterial activity obtained with different concentrations of $(\mathrm{A})$ diffuse agent (g/mL), and (B) non-diffuse agent $(\mathrm{g} / \mathrm{mL})$. The procedure was performed in triplicate for each bacterium in, at least, three independent assays $(\mathrm{n}=9)$. 
( $49 \%$ and $47 \%$ ), as shown in Fig. 3B. Based on these results, it appears that moisture levels represent a crucial parameter for assessing the antimicrobial activity of textiles, especially in the case of textiles coupled to non-diffusible antimicrobial agents.

Nutrients available on the wound site control the deposition and growth of microorganisms. Therefore, the medium used for the antimicrobial assessment of wound dressings affects their reaction response. A rich medium will enhance microorganism growth and false negatives may be unavoidable. Otherwise, if a poor medium is employed, the microorganism growth may be hindered and false positives may occur. The most suitable medium should have a $\mathrm{pH}$ value and nutrient content/concentrations similar to those found on human skin. Synthetic sweat formulations represent a viable option, since they have $\mathrm{pH}$ values similar to skin and also contain at least some of the most important biomolecules and minerals present in the wound environment.

With regard to the growth medium used, the findings of this study reveal that the antimicrobial activities of the textiles pre-treated with both agents were dependent on its nature, and also on the bacteria tested (Fig. 4). For instance, the diffusible agent-loaded textile had a similar K. pneumoniae death rate in TSB (diluted 20x) and the synthetic sweat solution (SSS), but a reduced effect against $S$. aureus when
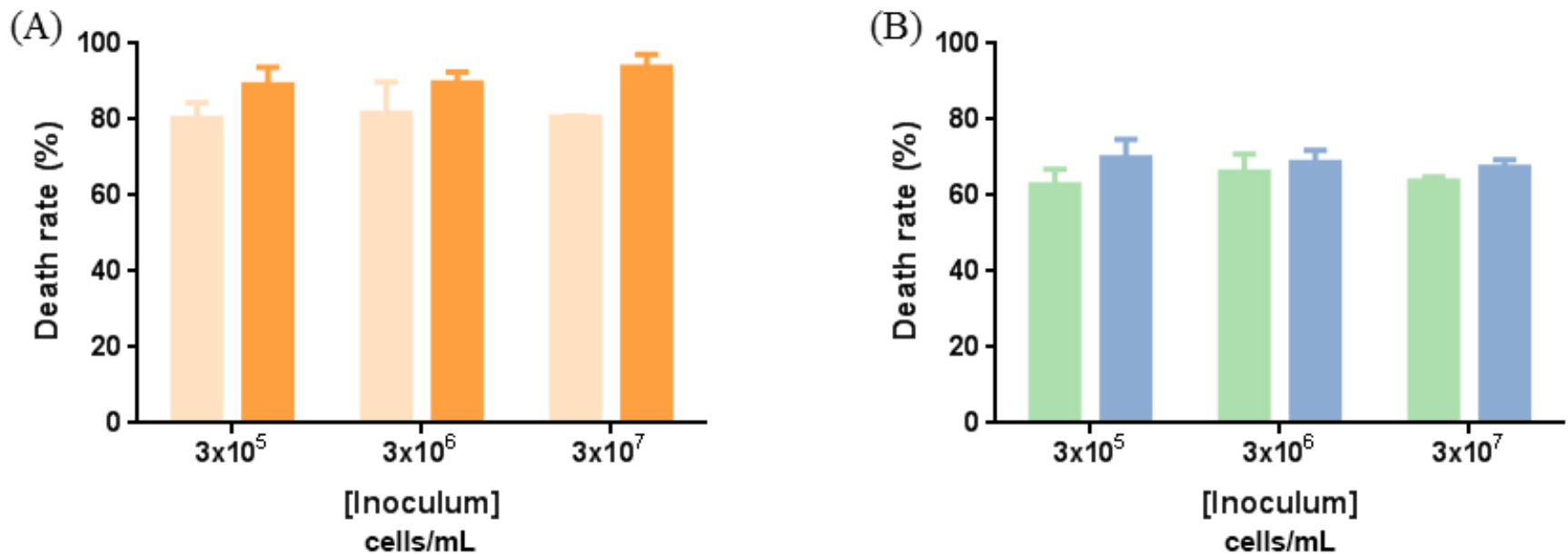

Fig. 2. Effect of the inoculum concentration on textile antibacterial activity. (A) Diffuse agent $(0.5 \mathrm{~g} / \mathrm{mL})$ and (B) non-diffuse agent $(0.205 \mathrm{~g} / \mathrm{mL})$. Lighter color: S. aureus and dark color $K$. pneumoniae ${ }^{*}$ statistically different from the $1 \times 10^{5}$ cells $/ \mathrm{mL}$ of inoculum. The procedure was made in triplicate for each bacterium in, at least, three independent assays $(n=9)$.
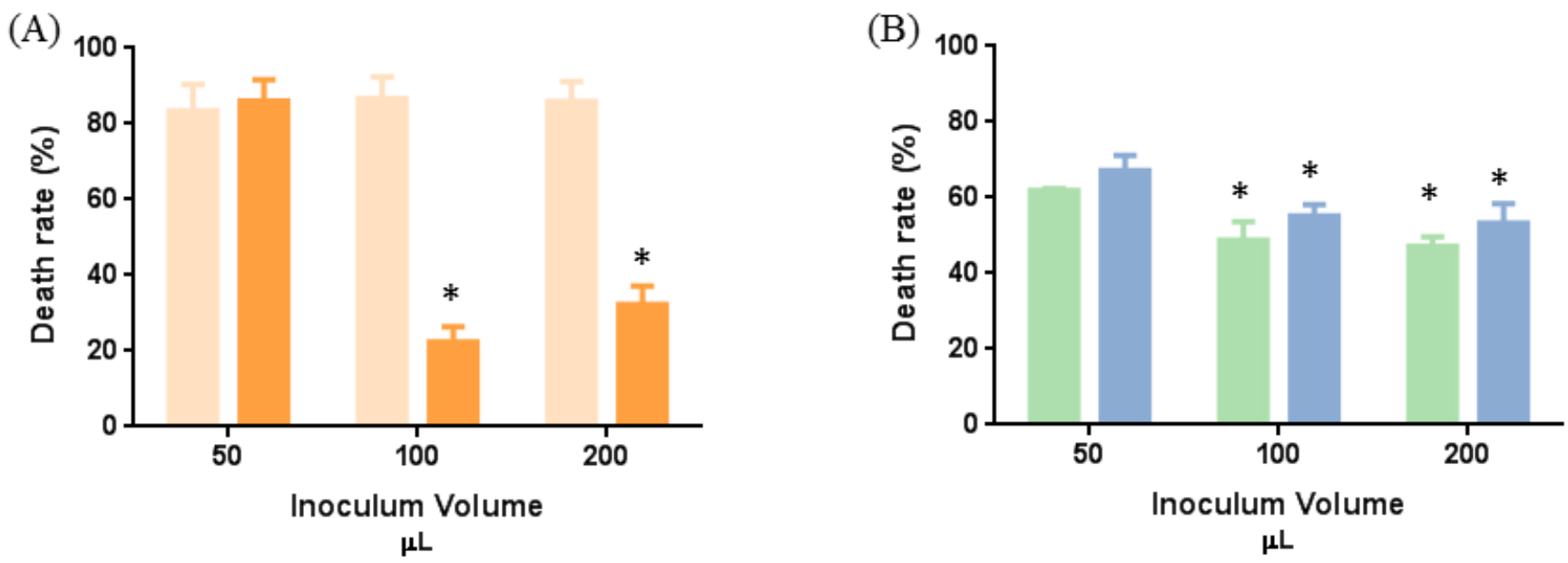

Fig. 3. Effect of the inoculum volume on textile antibacterial activity. (A) Diffuse agent $(0.5 \mathrm{~g} / \mathrm{mL})$ and (B) non-diffuse agent $(0.205 \mathrm{~g} / \mathrm{mL})$. Lighter color: $S$. aureus and dark color K. pneumoniae *statistically different from the $50 \mu \mathrm{L}$ of inoculum. The procedure was made in triplicate for each bacterium in, at least, three independent assays $(\mathrm{n}=9)$. 


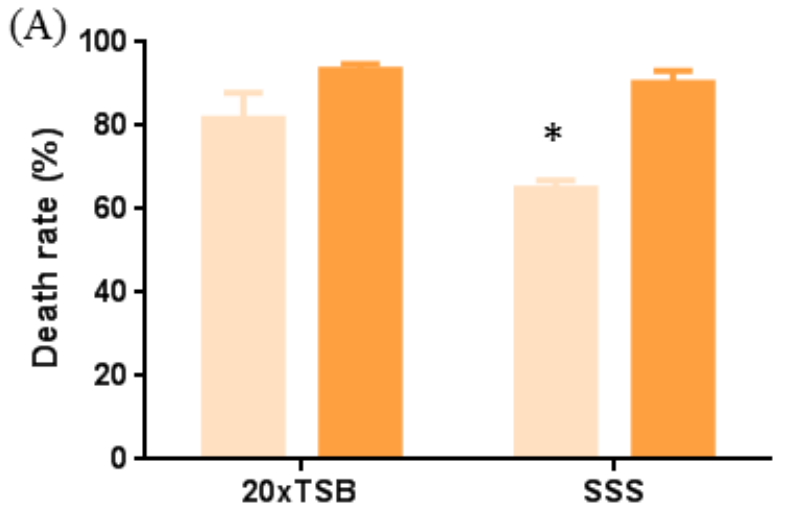

Medium

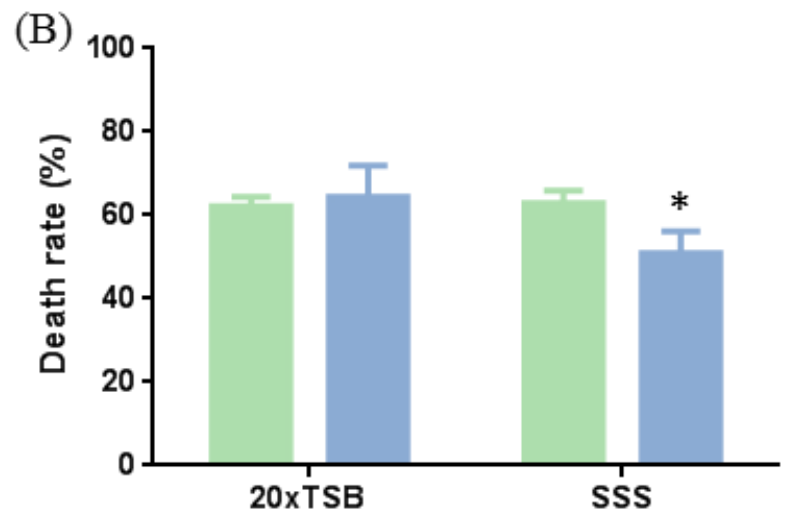

Medium

Fig. 4. Effect of the medium on textile antibacterial activity. (A) Diffuse agent $(0.5 \mathrm{~g} / \mathrm{mL})$ and (B) non-diffuse agent $(0.205 \mathrm{~g} / \mathrm{mL})$. Lighter color: S. aureus and dark color K. pneumoniae ${ }^{*}$ statistically different from the $50 \mu \mathrm{L}$ of inoculum. The procedure was made in triplicate for each bacterium in, at least, three independent assays $(n=9)$.

\begin{tabular}{|c|c|c|c|c|}
\hline Quantitative & AATCC & ISO & JIS L & Proposed Method \\
\hline Number & 100 & 20743 & 19002 & \\
\hline Date & 2012 & 2013 & 2008 & 2015 \\
\hline Title & $\begin{array}{l}\text { Antibacterial Finishes on Tex- } \\
\text { tile Materials: Assessment of }\end{array}$ & $\begin{array}{l}\text { Textiles-Determination of } \\
\text { Antibacterial Activity of Textile } \\
\text { Products (Adsorption Method) }\end{array}$ & $\begin{array}{l}\text { Testing for Antibacterial } \\
\text { Activity and Efficacy on Textile } \\
\text { Products-Quantitative Method } \\
\text { (Adsorption Test) }\end{array}$ & $\begin{array}{l}\text { Testing for Antibacterial Activity } \\
\text { and Efficacy on Textile Products for } \\
\text { Wound Dressing Application-Quan- } \\
\text { titative Method }\end{array}$ \\
\hline Scope & $\begin{array}{l}\text { Quantitative procedure for } \\
\text { the evaluation of the degree of } \\
\text { antibacterial activity. }\end{array}$ & $\begin{array}{l}\text { Determination of the antibacterial } \\
\text { activity of all antibacterial textile } \\
\text { products including nonwovens. } \\
\text { Applicable to all textile prod- } \\
\text { ucts, including cloth, wadding, } \\
\text { thread, and material for clothing, } \\
\text { bedclothes, home furnishings, and } \\
\text { miscellaneous goods, regardless of } \\
\text { the type of antibacterial agent used. }\end{array}$ & $\begin{array}{l}\text { Evaluation of the antibacterial } \\
\text { activity to bacteria on antibacte- } \\
\text { rial deodorant finished or mi- } \\
\text { crobial control finished textile } \\
\text { products (general use for the } \\
\text { household product and special } \\
\text { use for medical and equivalent } \\
\text { facilities). }\end{array}$ & $\begin{array}{l}\text { Quantitative procedure for the } \\
\text { evaluation of the degree of antibacte- } \\
\text { rial activity of textile to be used for } \\
\text { wound treatment. }\end{array}$ \\
\hline Microorganism & $\begin{array}{l}\text { S. aureus ATCC } 6538 \\
\text { K. pneumoniae ATCC } 4352 \\
\text { Other suitable species }\end{array}$ & $\begin{array}{l}\text { S. aureus ATCC } 6538 \\
\text { K. pneumoniae ATCC } 4352\end{array}$ & $\begin{array}{l}\text { S. aureus ATCC } 6538 \\
\text { Escherichia coli NBRC } 3301 \\
\text { K. pneumoniae ATCC } 4352 \\
\text { Pseudomonas aeruginosa NBRC } \\
3080 \\
\text { Methicillin resistant S. aureus } \\
\text { IID } 1677\end{array}$ & $\begin{array}{l}\text { S. aureus ATCC } 6538 \\
\text { K. pneumoniae ATCC } 4352 \\
\text { Other suitable species }\end{array}$ \\
\hline Inoculum Concentration & $1 \times 10^{5} \mathrm{CFU} / \mathrm{mL}$ & $1 \times 10^{5} \mathrm{CFU} / \mathrm{mL}$ & $1 \times 10^{5} \mathrm{CFU} / \mathrm{mL}$ & $3 \times 10^{7} \mathrm{CFU} / \mathrm{mL}$ \\
\hline Inoculum Volume & $1 \mathrm{~mL}$ & $0.2 \mathrm{~mL}$ & $0.2 \mathrm{~mL}$ & $0.2 \mathrm{~mL}$ \\
\hline Medium & NB; TSB; BHI; MHB & NB diluted $20 \times$ & Saline medium & Sweat acid solution \\
\hline Sample Size & $48 \mathrm{~cm}$ (circular) & $0.4 \mathrm{~g}$ (circular) & $0.4 \mathrm{~g}$ & $0.1 \mathrm{~g}$ \\
\hline Procedure & Better & Good & Good & Better \\
\hline Material and equipment & Good & Better & Better & Better \\
\hline Time (days) & 5 & 5 & 5 & 5 \\
\hline
\end{tabular}


SSS was used (65\% death cell, and $82 \%$ for the TSB (diluted 20x)). A different effect was observed for the non-diffusible agent. A similar death rate was achieved for $S$. aureus regardless of the medium used, and a reduced effect was observed when SSS was used in the K. pneumoniae incubations.

For all the environmental conditions tested, the diffusible agent showed a superior death rate when compared to that of the non-diffusible agent. As noted above, the non-diffusible antimicrobial agent is covalently-linked to the textile material, and their interaction with bacteria depends on the contact area and the agent concentrations available for these interactions. In contrast, diffusible agents can be liberated from the textile to the surrounding environment, and therefore their activities depend only on the textile content of these species. ${ }^{28,29}$ Hence, these agents may exhibit different behaviors, even under the same environmental conditions; for this reason, it was important to evaluate the activities of both non-diffusible and diffusible antimicrobial agents to validate the improvements made to the available methods.

\section{Conclusions}

In conclusion, the test method adjustments suggested in this work can be 1) successfully applied to both diffusing and non-diffusing antimicrobial agents, and also for Grampositive and Gram-negative bacteria, and 2) performed under test conditions similar to those found on most types of wounds (exudate, infected skin, and sweat).

From the adaptations suggested, moisture levels werefound to exert the greatest effect on the activities of the antibacterial textiles used. Therefore, further studies should incorporate high levels of moisture to predict the tested textile's behavior under wound exudate conditions. Nevertheless, the medium also modifies the efficacies of antibacterial textiles, and therefore the synthetic sweat solution appears to represent a viable option to predict the effect of the textiles on an infected wound.

The present study recommends some adjustments to the test method used to assess the antibacterial activities of textiles (Table I). These allow a more realistic analysis of their behavior when in contact with infected wounds.

\section{Acknowledgements}

We thank Jorge Santos for helping with the textile samples. The authors are grateful for the FCT Strategic Project PEst-OE/EQB/LA0023/2013 and the Project "BioHealthBiotechnology and bioengineering approaches to improve health quality," Ref. NORTE-07-0124-FEDER-000027, co-funded by the Programa Operacional Regional do Norte (ON.2-O Novo Norte), QREN, FEDER. The authors also acknowledge the project Consolidating Research Expertise and Resources on Cellular and Molecular Biotechnology at CEB/IBB, Ref. FCOMP-01-0124- FEDER-027462. This work was also funded by FEDER funds through the Operational Program for Competitiveness Factors-COMPETE and National Funds through FCT-Foundation for Science and Technology under the project PEst-C/CTM/UI0264/2011. Additionally, the authors would like to thank the FCT for the grant to E. Pinho (SFRH/BD/62665/2009), and also to the Foundation for Science and Technology (Portugal) for financial support to the research Centre CEB and E. Pinho grant (SFRH/ BD/62665/2009).

\section{References}

1. Harding, K. G.; Jones, V.; Price, P. Diabetes/Metabolism Research and Reviews 2000, 16 (1), 47-50.

2. Ather, S.; Hargding, K. Wound Management and Dressings. In Advanced Textiles for Wound Care, 1st edition; Rajendran, S., Ed.; Woodhead Publishing Limited: Cardiff, UK, 2009; pp 3-19.

3. Kokabi, M.; Sirousazar, M.; Hassan, Z. M. European Polymer Journal 2007, 43, 773-781.

4. Ovington, L. G. Clinical Dermatology 2007, 25, 33-38.

5. Boateng, J. S.; Matthews, K. H.; Stevens, H.; Eccleston, G. M. Journal of Pharmaceutical Science 2008, 97, 2892-2923.

6. Chen, L.; Wu, J.; Yuwen, L.; Shu, T.; Xu, M.; Zhang, M.; Yi, T. Langmuir 2009, 25, 8434-8438.

7. Shores, J.; Gabriel, A.; Gupta, S. Advances in Skin Wound Care 2007, 20, 493-506.

8. Wu, J.; Hou, S.; Ren, D.; Mather, P. Biomacromolecules 2009, 10, 2686-2693.

9. Pinho, E.; Magalhães, L.; Henriques, M.; Oliveira, R. Annals of Microbiology 2010, 61, 493-498.

10. Ramachandran, T.; Rajendrakumar, K.; Rajendran, R. The Institution of Engineers, India, Journal of Textile Engineering 2004, 8, 42-47.

11. JIS L 1902:2008, Testing for Antibacterial Activity and Efficacy on Textile Products, Japanese Industrial Standard, 2008.

12. Liu, X.; Lin, T.; Fang, J.; Yao, G.; Zhao, H.; Dodson, M.; Wang, X. Journal of Biomedical Materials Research, Part A 2010, 94, 499-508.

13. Mahltig, B.; Fiedler, D.; Simon, P. Journal of Textile Institute 2011, 102, 739-745.

14. Mikhaylova, A.; Liesenfeld, B.; Moore, D.; Toreki, W.; Vella, J.; Batich, C.; Schultz, G. Wounds 2011, 23, 24-31.

15. Gallant-Behm, C.; Yin, H.; Liu, S.; Heggers, J.; Langford, R.; Olson, M.; Hart, D.; Burrell, R. Wound Repair and Regeneration 2005, 13, $412-421$.

16. Montazer, M.; Alimohammadi, F.; Shamei, A.; Rahimi, M. Colloids and Surfaces B: Biointerfaces 2012, 89, 196-202.

17. Cai, Z.; Mo, X.; Zhang, K.; Fan, L.; Yin, A.; He, C.; Wang, H. International Journal of Molecular Sciences 2010, 11, 3529-3539.

18. Qin, Y. Journal of Apply Polymer Science 2008, 107, 993-999.

19. Teufel, L.; Pipal, A.; Schuster, K.; Staudinger, T.; Redl, B. Journal of Applied Microbiology 2010, 108, 450-461.

20. Shahid, M.; Ahmad, A.; Yusuf, M.; Khan, M.; Khan, S.; Manzoor, N.; Mohammad, F. Dyes and Pigments 2012, 95 (1), 53-61.

21. Borkow, G.; Okon-Levy, N.; Gabbay, J. Wounds 2010, 22, 301-310.

22. Liu, X.; Lin, T.; Gao, Y.; Xu, Z.; Huang, C.; Yao, G.; Jiang, L.; Tang, Y.; Wang, X. Journal of Biomedical Materials Research, Part B 2012, 100, 1556-1565.

23. Wiegand, C.; Heinze, T.; Hipler, U. Wound Repair and Regeneration 2009, 17, 511-521. 
24. Perelshtein, I.; Applerot, G.; Perka, N.; Grinblat, J.; Gedanken, A. Chemistry-A European Journal 2012, 18, 4575-4582.

25. Simović, L.; Škundrić, P.; Kostić, M.; Tasić, G.; Kojić, Z.; Milaković, B.; Medović, A. Journal of Applied Polymer Science 2011, 120, 1459-1467.

26. Arakawa, H.; Neault, J.; Tajmir-Riahi, H. Biophysical Journal 2001, 81, 1580-1587.

27. Phillips, P.; Sampson, E.; Yang, Q.; Antonelli, P.; Progulske-Fox, A.; Schultz, G. Wound Healing Southern Africa 2008, 1 (2), 10-12.

28. Gao, Y.; Cranston, R. Textile Research Journal 2008, 78, 60-72.

29. Thorn, R.; Greenman, J.; Austin, A. Journal of Applied Microbiology 2005, 99, 895-901.

\section{Author}

Eva Pinho holds a Ph.D. in Biomedical Engineering at the University of Minho in collaboration with Bolton University, UK. Her research interests involve encapsulation of antimicrobial agents for functionalization of materials, including textiles, hydrogels, and hard surfaces. Her work includes development of carriers for antimicrobial agents, their application on materials and physicochemical and biological evaluation of the functionalized materials. She has several publications in peer-reviewed journals and conference proceedings.

Eva Pinho, CEB, Centre for Biological Engineering, LIBRO - Laboratório de Investigacão em Biofilmes Rosário Oliveira, University of Minho, Campus Gualtar, 4710-057 Braga, Portugal; phone +351.253 .604 .401 ; fax +351.253 .604 .429 ; evapinho@deb.uminho.pt.

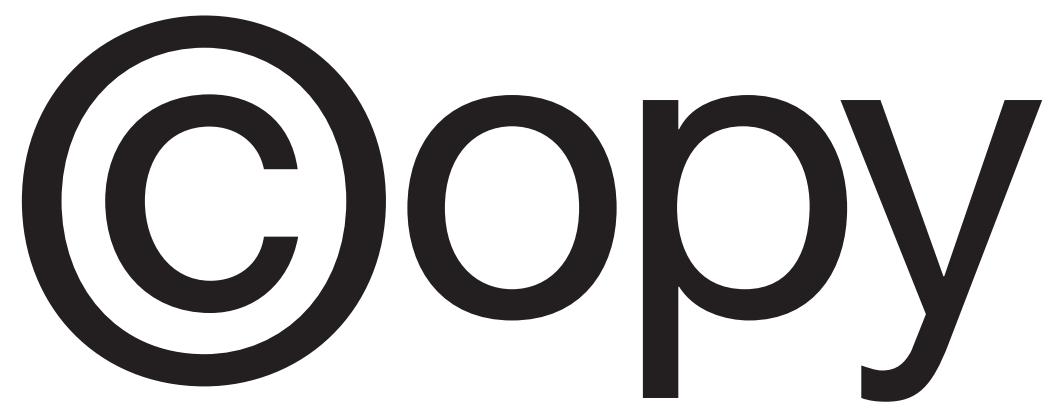

What you're reading is more than just copy. It's also copyrighted. So before you head over to the photocopier, make sure you have permission. Contact the publisher or visit www.copyright.com.

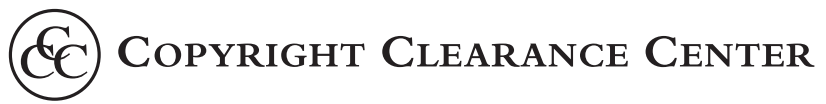

